\title{
Calidad de leche acopiada de pequeñas ganaderías de Cotopaxi, Ecuador
}

\author{
Quality of milk collected in small farms of Cotopaxi, Ecuador \\ Deysi Guevara-Freire ${ }^{1,2}$, Mayra Montero-Recalde ${ }^{1}$, Alison Rodríguez', \\ Luciano Valle ${ }^{1}$, Diana Avilés-Esquivel ${ }^{1}$
}

\section{Resumen}

Se analizó la calidad composicional, fisicoquímica e higiénica de la leche cruda acopiada en dos empresas procesadoras de lácteos en Cotopaxi, Ecuador, y se comparó con las normativas ecuatorianas. Se seleccionaron 10 proveedores por empresa para un total de 210 muestras por empresa colectadas en 21 días consecutivos. La calidad composicional (grasa) se midió con base a la norma INEN 0012, para la calidad fisicoquímico se utilizaron los métodos de análisis de las normas INEN 0009, INEN 0011, INEN 0013, CONVENIN 1315-79. Para la calidad higiénica se utilizó la norma AOAC 990.12 y para determinar residuos de antibiótico se usó el kit AuroFlow BTS Combo Strip Test. Las variables de acidez, materia grasa, densidad relativa, color, olor, aspecto, $\mathrm{pH}$ y antibiótico mostraron cumplimiento de la normativa ecuatoriana y no presentaron diferencias significativas entre las empresas receptoras. Contrariamente, el contenido de grasa y $\mathrm{pH}$ fueron diferentes entre las empresas $(\mathrm{p}<0.05)$. La calidad higiénica de la leche reportó un alto recuento de microorganismos aerobios mesófilos $(7.58 \mathrm{E}+07 \mathrm{UFC} / \mathrm{ml}$ y $8.02 \mathrm{E}+07$ $\mathrm{UFC} / \mathrm{ml}$ ) sin diferencias entre empresas. En conclusión, la mayoría de los parámetros de calidad fisicoquímica y composicional de la leche proveniente de unidades de producción familiar se ajustan a la normativa nacional, a excepción de la temperatura y la calidad microbiológica, resultados que se le atribuye a la inadecuada práctica de ordeño y almacenamiento de la leche.

Palabras clave: calidad; productor; leche cruda; contaminación; Bos taurus

\footnotetext{
${ }^{1}$ Facultad de Ciencias Agropecuarias, Universidad Técnica de Ambato, Cevallos, Tungurahua, Ecuador

${ }^{2}$ E-mail: da.guevara@uta.edu.ec
}

Recibido: 1 de mayo de 2018

Aceptado para publicación: 17 de noviembre de 2018 
The compositional, physicochemical and hygienic quality of the raw milk collected in two dairy plants in Cotopaxi, Ecuador was analyzed and compared with the Ecuadorian regulations. Ten suppliers were selected per company for a total of 210 samples per dairy plant in 21 consecutive days. The compositional quality (fat) was measured with the INEN 0012 standard, for the physicochemical quality the analysis methods of the standards INEN 0009, INEN 0011, INEN 0013, CONVENIN 1315-79 were used. For hygienic quality was used the AOAC 990.12 standard and to determine antibiotic residues the AuroFlow BTS Combo Strip Test kit was used. The variables of acidity, fat, relative density, color, odor, aspect, $\mathrm{pH}$ and antibiotic residues showed compliance with the Ecuadorian regulations and did not show significant differences between the dairy plants. Conversely, the fat and $\mathrm{pH}$ content were different between the dairy plants $(p<0.05)$. The hygienic quality of the milk reported a high count of mesophilic aerobic microorganisms $(7.58 \mathrm{E}+07 \mathrm{CFU} / \mathrm{ml}$ and $8.02 \mathrm{E}+07 \mathrm{CFU} / \mathrm{ml})$ without differences between dairy plants. In conclusion, most of the parameters of physicochemical and compositional quality of milk from smallholder producers are adjusted to national regulations, except for temperature and microbiological quality, results attributed to the inadequate milking and milk storage procedures.

Key words: quality; producer; raw milk; contamination; Bos taurus

\section{INTRODUCCIÓN}

La producción lechera en Ecuador se inicia en 1950 a partir de ganado importado Holstein, Pardo Suizo, Brown Swiss y la venta de pie de crías (Vizcarra, 2015). En 1970, la transformación tecnológica de las haciendas ganaderas de la sierra norte y centro del país, sumado al apoyo político del gobierno nacional, privilegiaron al sector ganadero (Brassel y Hidalgo, 2007). Sin embargo, el tema de valoración del litro de leche por calidad no fue política de estado hasta 2010 con el Acuerdo Ministerial N. ${ }^{\circ} 136$, donde se establece «pagar el precio mínimo de sustentación de US\$ 0.3933 , más lo estipulado en la tabla oficial referencial de pago por componentes e higiene, además, de incentivos adicionales al acuerdo» (Ministerio de Agricultura, Ganadería, Acuacultura y Pesca, 2010).

En la actualidad, los precios de venta del litro de leche están en dependencia de las exigencias de calidad de las empresas de lácteos o de la forma de comercialización. Así, si la compra la realiza el Centro de Acopio le cancela al productor entre US\$ 0.36 y 0.45 por litro de leche acopiada. En cantones de la región Sierra los precios fluctúan entre US\$ 0.32 hasta 0.48 , pudiendo llegar a 0.50 cuando la extensión de la Unidad de Producción Agropecuaria (UPA) sea mayor a 20 ha (Requelme y Bonifaz, 2012). A pesar de existir una política pública de pago, los productores son remunerados con valores inferiores a causa de la excesiva intermediación y limitadas condiciones de comercio (Pico, 2015).

En la zona centro de la Sierra ecuatoriana se contabiliza alrededor de $200000 \mathrm{l} /$ día de leche producida por sistemas familiares de campesinos asociados. Solo en la provincia de Tungurahua se generan $10573 \mathrm{l} /$ día y en la provincia Cotopaxi 12250 1/día con promedio de 5.51 /vaca/día (Pico, 2015). Estas zonas se caracterizan por un sistema de crianza tradicional (Pico, 2015) de ganado criollo y mestizo producto del cruce de razas Holstein, Brown Swiss y Jersey (Vizcarra, 2015), con una alimentación basada en mez- 
clas forrajeras de alfalfa, raigrás, trébol, vicia y avena (Pico, 2015).

El método de ordeño es tradicional en un $92.0 \%$ y mecánico en un $7.1 \%$, con un tiempo de rutina de ordeño que oscila entre 5 a 10 minutos por vaca, y la leche es generalmente enfriada y entregada a los intermediarios o centros de acopio (Bonifaz y Requelme, 2011). La leche cruda es destinada al consumo fresco (39\%) y elaboración de los derivados lácteos (35\% a queserías), mientras que un $25 \%$ es sometido a procesos industriales $(19 \%$ de leche pasteurizada y $6 \%$ en derivados) y apenas un $1 \%$ se comercializa a Colombia (Pico, 2015).

En Ecuador, el precio establecido por los intermediarios no está en relación con la calidad de la leche, puesto que el principal interés está dirigido al volumen total del líquido, dejando a un lado la calidad bacteriológica y el contenido de sólidos (proteína y grasa), a pesar de existir controles por parte de organismos gubernamentales que vigilan la inocuidad de los alimentos. El problema de la deficiente calidad sanitaria de leche es evidente, un claro ejemplo es el consumo y comercialización de leche procedente de animales enfermos o en tratamiento farmacológico (Bonifaz y Requelme, 2011). Al existir pocos estudios sobre la calidad de leche, el objetivo del presente estudio fue realizar una comparación fisicoquímica y composicional (temperatura, acidez, $\mathrm{pH}$, densidad, grasa y antibiótico) y microbiológica (aerobios mesófilos) de leche cruda proveniente de sistemas campesinos asociados y comercializada en dos empresas lácteas de la provincia de Cotopaxi, Ecuador para compararla con las normas del Servicio Ecuatoriano de Normalización (INEN).

\section{Materiales y Métodos}

El estudio se desarrolló en dos plantas procesadoras de leche ubicadas en la provincia de Cotopaxi-Ecuador en el mes de abril.
En cada empresa se seleccionaron a 10 proveedores fijos, que a su vez recogían la leche cruda de 25 pequeños productores en promedio de las localidades de Cusubamba, Mulalillo, Belisario Quevedo, Antonio José Holguín, Panzaleo, Huapante, haciendo una población de 500 productores por las dos empresas. La selección de los proveedores fue hecha mediante un muestreo discrecional, tomando en consideración solo aquellos proveedores con un volumen de total de $\geq 160$ 1/día/proveedor.

Para el muestreo se tomó una muestra por día de leche cruda de 10 proveedores por empresa durante tres semanas consecutivas, haciendo un total de 210 muestras por empresa. La recolección de las muestras se realizó de acuerdo con la Norma Oficial Ecuatoriana INEN 0004 (1984). Para el análisis composicional y fisicoquímico de la leche se tomó una muestra de $750 \mathrm{ml}$ por tanque de cada proveedor, mientras que para el análisis bacteriológico se tomó una muestra en frascos estériles de $50 \mathrm{ml}$ de todos los tanques receptados/proveedor. Las muestras se colocaron en un recipiente en condiciones de refrigeración, evitando exposición directa del producto a la luz durante el transporte.

En cada muestra se analizaron parámetros sobre composición de la leche (contenido de grasa) así como parámetros de calidad fisicoquímica cualitativos (color, aspecto y olor de la leche) y cuantitativos (temperatura, densidad, $\mathrm{pH}$, acidez y presencia de antibióticos). La muestra compuesta/proveedor para el análisis de la calidad higiénica referida al contenido de aerobios mesófilos y antibiótico se analizó a los 7, 14 y 21 días. La calidad microbiológica se determinó en el laboratorio certificado LACONAL (Laboratorio de Control y Análisis de Alimentos).

La calidad composicional se analizó mediante pruebas de materia grasa por el método de Gerber (INEN 0012, 1973). Para la evaluar el color, aspecto y olor de la leche se utilizó la norma INEN 0009 (2008), el pH mediante la norma CONVENIN 1315-79 
(1979), la prueba de densidad a $15^{\circ} \mathrm{C}$ con termo-lactodensímetro de Quevenne (INEN 0011, 1984) y la acidez mediante titulación con $\mathrm{NaOH}$ 0.1N (INEN 0013, 1984). La presencia de antibióticos fue analizada a través del kit AuroFlow BTS Combo Strip Test (Bioo Scientific), cuyo fin es detectar betalactámicos, tetraciclinas y residuos de antibióticos de sulfonamida. La evaluación higiénica se realizó en base a lo establecido por la AOAC 990.12 mediante el recuento de aerobios mesófilos por siembra en Petrifilms.

Adicionalmente se aplicó una entrevista estructurada a 46 pequeños productores de una población de 500 en los meses de abrilmayo en las localidades antes descritas. El criterio de selección de los productores fue el cumplimiento en la entrega del volumen total de leche (sin intermediarios) y el compromiso con la asociatividad comercial que tienen con los proveedores (cumplimiento en pago). Se empleó la metodología de Herrera et al. (2004) para el cálculo del tamaño muestral. Las variables estudiadas en la entrevista fueron raza, número de animales en el rebaño, tipo de ordeño, producción vaca/día, tipo de alimentación y prácticas de ordeño. Con respecto al cuestionario de la entrevista se realizó un piloto a un grupo de productores que no pertenecía a la muestra seleccionada, pero con características similares. Para el diseño de la encuesta se utilizó el modelo empleado por Peláez (2003) y Bonifaz y Requelme (2011), la cual se muestra en el Cuadro 1.

Para el análisis estadístico se utilizó el programa SPSS v. 20 mediante el uso de estadística descriptiva, con comparación $t$ de Student para determinar diferencias significativas entre promedios.

\section{Resultados}

En el Cuadro 1 se muestran los resultados de la entrevista aplicada a los productores. Los sistemas de producción de leche con razas Holstein, criollo y mestiza (criollo $\mathrm{x}$ Holstein) en las dos empresas se desarrollaron con pasturas basadas en leguminosas, gramíneas, balanceado y la mezcla de balanceado con forraje. El ordeño es manual con un rango de producción de 2 a 80 1/día. El hato lechero varía de 1 a 11 vacas. En cuanto a las prácticas de ordeño y limpieza de utensilios, pocos productores practican la estimulación de la ubre con ternero, mientras que la mayor parte usan agua para la desinfección de las ubres, sellado y una sola toalla de papel reutilizable en el secado. La leche es preferentemente almacenada en bidones plásticos y los utensilios son limpiados con detergente y cloro comercial en su mayoría.

En el Cuadro 2 se muestra la calidad fisicoquímica y composicional de la leche cruda recibida en las dos empresas procesadoras de leche. La leche cruda recibida cumple con los parámetros de calidad de la norma INEN 0009 en cuanto a los parámetros de densidad relativa, acidez titulable, materia grasa, color, olor, aspecto y residuos de antibióticos. Sin embargo, los recuentos de mesófilos aerobios se encuentran por encima de la norma INEN y sin diferencia significativa entre las empresas.

$\mathrm{El} \mathrm{pH}$ de la leche fue mayor en la empresa $1(\mathrm{p}<0.05)$, mientras que no hubo diferencias significativas en la acidez titulable, densidad y temperatura registradas entre las dos empresas. La acidez titulable registró valores entre 0.14 y $0.15 \%$, lo cual está por debajo del rango aceptado por la norma ecuatoriana (INEN 0013, 1984). Los parámetros físicos de color, aspecto y olor estuvieron de acuerdo con la noma INEN 0009 (2008), la cual establece entre sus características una leche de color blanco opalescente o ligeramente amarillento, de olor suave, lácteo característico, libre de olores extraños; además de un aspecto homogéneo y libre de materias extrañas. Contrariamente, la temperatura resultó cuatro veces superior a lo indicado en la norma COVENIN 903-93, con una ligera diferencia entra las dos empresas. El contenido de grasa de la leche fue mayor en la empresa 1 con relación a la empresa 2 $(\mathrm{p}<0.05$; Cuadro 2). 
Cuadro 1. Resultados de la encuesta aplicada a productores de pequeñas ganaderías en Cotopaxi, Ecuador

\begin{tabular}{|c|c|c|c|}
\hline \multirow{2}{*}{ Variables } & & \multicolumn{2}{|c|}{ Valores (\%) } \\
\hline & & Empresa 1 & Empresa 2 \\
\hline \multirow[t]{3}{*}{ Raza del ganado } & Holstein & 83 & 70 \\
\hline & Mestiza & 17 & 15 \\
\hline & Criollo & 0 & 15 \\
\hline \multirow{2}{*}{$\begin{array}{l}\text { Tamaño del hato } \\
\text { (vacas) }\end{array}$} & $1-6$ & 93 & 83 \\
\hline & $7-11$ & 7 & 17 \\
\hline \multirow[t]{3}{*}{ Producción (1) } & $2-40$ & 30 & 20 \\
\hline & $10-50$ & 40 & 50 \\
\hline & $15-80$ & 30 & 30 \\
\hline \multirow{4}{*}{$\begin{array}{l}\text { Alimentación del } \\
\text { ganado }\end{array}$} & Leguminosas & 46 & 30 \\
\hline & Gramíneas & 41 & 63 \\
\hline & Balanceado & 7 & 7 \\
\hline & Balanceado y forraje & 7 & 0 \\
\hline \multirow[t]{2}{*}{ Tipo de ordeño } & Manual & 100 & 100 \\
\hline & Mecánico & 0 & 0 \\
\hline \multirow{2}{*}{$\begin{array}{l}\text { Estimulación del } \\
\text { ordeño }\end{array}$} & Uso de ternero & 4 & 11 \\
\hline & No usa ternero & 96 & 89 \\
\hline \multirow{2}{*}{$\begin{array}{l}\text { Desinfección de las } \\
\text { ubres }\end{array}$} & Yodo & 39 & 13 \\
\hline & Agua & 61 & 87 \\
\hline \multirow{2}{*}{ Secado de la ubre } & Toalla reutilizable & 76 & 80 \\
\hline & Toalla de tela & 24 & 20 \\
\hline \multirow[t]{2}{*}{ Uso de toalla/secado } & Todas las vacas & 85 & 74 \\
\hline & Algunas & 15 & 26 \\
\hline \multirow[t]{3}{*}{ Sellado de las ubres } & Sí & 59 & 78 \\
\hline & No & 41 & 22 \\
\hline & Plásticos & 63 & 43 \\
\hline \multirow{2}{*}{$\begin{array}{l}\text { Tipo de } \\
\quad \text { almacenamiento }\end{array}$} & Tanque de acero inoxidable & 7 & 15 \\
\hline & Tanque de aluminio & 30 & 41 \\
\hline \multirow{3}{*}{$\begin{array}{l}\text { Limpieza de los } \\
\text { recipientes }\end{array}$} & Detergente & 61 & 83 \\
\hline & Cloro & 28 & 15 \\
\hline & Ambos & 11 & 2 \\
\hline
\end{tabular}

En el análisis de residuos de antibióticos no se apreció diferencia significativa en las muestras de las dos empresas; sin embargo, se obtuvo un resultado positivo a betalactámicos, por lo que la empresa descartó esa leche para dar cumplimiento a lo indicado en las Normas INEN.

\section{Discusión}

El contenido de grasa reportado en las dos empresas mostró una diferencia significativa de $0.3 \%$ entre ellas, lo que sugiere que el hato ganadero y la alimentación pudieron 
Cuadro 2. Calidad fisicoquímica, composicional e higiénica de leche cruda de vaca acopiada por dos industrias procesadoras de Cotopaxi, Ecuador, y su comparación con normas de calidad ( $\mathrm{n}=210$ muestras por empresa)

\begin{tabular}{|c|c|c|c|c|c|}
\hline $\begin{array}{c}\text { Análisis } \\
\text { realizado }\end{array}$ & $\begin{array}{c}\text { Empresa } 1 \\
\text { (media) }\end{array}$ & $\begin{array}{c}\text { Empresa } 2 \\
\text { (media) }\end{array}$ & t Student & Normas & Calif. \\
\hline Color & LA & LA & & $\mathrm{LA}^{1}$ & 1 \\
\hline Aspecto & $\mathrm{H}$ & $\mathrm{H}$ & & $\mathrm{H}^{1}$ & 1 \\
\hline Olor & $\mathrm{LC}$ & $\mathrm{LC}$ & & $\mathrm{LC}^{1}$ & 1 \\
\hline $\begin{array}{l}\text { Temperatura } \\
\left({ }^{\circ} \mathrm{C}\right)\end{array}$ & $\begin{array}{l}20.02 \pm 1.1 \\
(10.7-25.3)\end{array}$ & $\begin{array}{c}21.6 \pm 2.0 \\
(20.3-23.3)\end{array}$ & $-0.86^{\mathrm{ns}}$ & $5^{2}$ & 0 \\
\hline $\mathrm{pH}$ & $\begin{array}{l}6.7 \pm 0.1^{\mathrm{a}} \\
(6.6-6.8)\end{array}$ & $\begin{array}{l}6.4 \pm 0.1^{\mathrm{b}} \\
(6.3-6.4)\end{array}$ & $6.17 * *$ & & 1 \\
\hline $\begin{array}{l}\text { Densidad } \\
\text { relativa }\end{array}$ & $\begin{array}{c}1.030 \pm 0.0018^{\mathrm{a}} \\
(1.028-1.032)\end{array}$ & $\begin{array}{c}1.029 \pm 0.00028^{\mathrm{b}} \\
(1.028-1.029)\end{array}$ & $1.94 *$ & $\begin{array}{l}1.029- \\
1033^{1}\end{array}$ & 1 \\
\hline $\begin{array}{l}\text { Acidez } \\
\text { titulable como } \\
\text { ácido láctico } \\
(\%) \text { (fracción } \\
\text { de masa) }\end{array}$ & $\begin{array}{c}0.15 \pm 0.003 \\
(0.14-0.15)\end{array}$ & $\begin{array}{c}0.14 \pm 0.004 \\
(0.14-0.15)\end{array}$ & $1.342^{\mathrm{ns}}$ & $\begin{array}{l}0.13- \\
0.17^{1}\end{array}$ & 1 \\
\hline $\begin{array}{l}\text { Materia grasa } \\
(\%) \text { (fracción } \\
\text { de masa) }\end{array}$ & $\begin{array}{l}3.4 \pm 0.1^{b} \\
(3.3-3.5)\end{array}$ & $\begin{array}{l}3.7 \pm 0.1^{\mathrm{a}} \\
(3.6-3.9)\end{array}$ & $-6.841 * *$ & $\begin{array}{c}3.0 \\
\text { (Mínimo) }^{1}\end{array}$ & 1 \\
\hline $\begin{array}{l}\text { Recuento de } \\
\text { mesófilos } \\
\text { aerobios } \\
\text { (UFC/ml) }\end{array}$ & $\begin{array}{c}7.58 \mathrm{E}+07 \pm \\
3.31 \mathrm{E}+07\end{array}$ & $\begin{array}{c}8.02 \mathrm{E}+07 \pm \\
3.85 \mathrm{E}+07\end{array}$ & $-0.206^{\mathrm{ns}}$ & $\begin{array}{c}1.5 \times 10^{6} \\
(\text { Maximo) }\end{array}$ & 0 \\
\hline Antibiótico $^{3}$ & Negativo & Negativo & & Ausencia $^{1}$ & 1 \\
\hline
\end{tabular}

LA: Ligeramente amarillento; H: Homogéneo; LC: Lácteo característico

Valores entre paréntesis indican los valores máximos y mínimos observados

ns: no significativo; *: $p<0.05 ;{ }^{* *}: \mathrm{p}<0.01$

${ }^{1}$ Norma INEN 0009 (2008)

${ }^{2}$ Leche cruda enfriada para el transporte a temperatura $<5$ 으 (Norma CONVENIN 903-93)

Calif: calificación (0: no cumple; 1 : sí cumple)

${ }^{3}$ Tamaño de muestra (30 muestras en cada análisis/empresa)

ser las causas destacables en las diferencias registradas. Harvatine et al. (2009) mencionan que la grasa es el componente con mayor variabilidad y sus cambios obedecen a factores nutricionales, genéticos y medio ambientales.

El contenido de grasa de la leche estuvo largamente por encima del valor mínimo requerido $(3.0 \%)$, lo cual podría estar rela- cionado con factores atribuibles a la raza (Bobe et al., 2007; Rojas et al., 2011). En la empresa 1 se recibe leche proveniente principalmente de vacas de raza mestiza (criollo $x$ Holstein), mientras que en la empresa 2 proviene mayormente de vacas criollas, mestizas y Holstein. Se tienen reportes que indican que la leche de vacas criollas presenta porcentajes de grasa entre 4.7 y $5.7 \%$ (Bobe et al., 2007; Rojas et al., 2011), mientras que 
la leche de vacas Holstein contiene entre 3.2 y $3.5 \%$ (Bartl et al., 2008). Harvatine et al. (2009) explica que la grasa es el componente con mayor variabilidad por causa de la alimentación. En el estudio se muestra una alimentación en su mayoría basada en gramíneas y leguminosas, con un mayor aporte de estas especies forrajeras en la alimentación de los bovinos pertenecientes a los productores de la empresa 2.

Según Bernal et al. (2007), la alimentación basada en forrajes de praderas que contengan gramíneas y leguminosas aumenta el contenido de grasa en la leche, pero la grasa disminuye si el forraje es muy joven debido a la falta de fibra. El uso de gramíneas disminuye en porcentaje de grasa en un $4.4 \%$ en vacas Holstein en pastoreo (Petit, 2002). Por otro lado, la alimentación a base de concentrado y heno presenta valores de grasa de $4.0 \%$, ensilado ryegrass de $3.4 \%$ y heno de pastizal natural de $3.7 \%$ (Ferlay et al., 2006).

La calidad fisicoquímica de la leche, relacionada con la densidad relativa y contenido de grasa, cumplió la norma de calidad INEN en ambas empresas receptoras. El gobierno ecuatoriano establece un estricto control de la calidad fisicoquímica de la leche y penaliza su incumplimiento a través de diferenciación en el precio, en el caso de estar fuera de los límites establecidos (Contero, 2008). En tal sentido, Magariños (2000) explica que el pago de la leche debe ser fijado en función a su calidad real, de manera de generar estímulos que favorezcan la mejora de la composición nutritiva y sanitaria de la leche. Por otro lado, Linn (1989) indica que a mayor producción de leche se tiende a una dilución de sus componentes, incluyendo la grasa. En el presente estudio se observó que el volumen de leche es bajo, lo que sugiere un incremento en el contenido de grasa.

A pesar de que las evaluaciones fueron realizadas en época húmeda, con predominancia de temperaturas más frescas, la leche fue manejada a temperaturas superiores a las exigencias fijadas por los organismos de control $\left(<5^{\circ} \mathrm{C}\right)$. Esta condición favorecería el crecimiento bacteriano en la leche y en consecuencia la acidificación y precipitación de la caseína, lo cual repercute en la elaboración de los derivados lácteos (Arango et al., 2011; Mariscal et al., 2013). En este sentido, Margariños (2000) afirma que la leche manejada a $15.5^{\circ} \mathrm{C}$ y bajo condiciones de higiene deficiente mostró incremento de su contenido microbiano (de 136533 hasta $24673571 \mathrm{UFC} / \mathrm{ml}$ a las $24 \mathrm{~h}$ ), mientras que a temperaturas de $4{ }^{\circ} \mathrm{C}$ el contenido microbiano a las $24 \mathrm{~h}$ fue solo de 281546 $\mathrm{UFC} / \mathrm{ml}$

Las bacterias aerobias mesófilas son aquellas que se desarrollan a temperatura ambiente y corporal, y se asocian con agentes etiológicos de la mastitis o la flora normal de la piel (Calderón et al., 2006). En tal sentido, el recuento de microorganismos mesófílicos determina las condiciones de higiene de la leche. En este estudio se observaron valores hasta 50 veces más del límite permitido en la norma ecuatoriana $\left(1.5 \times 10^{6}\right.$ $\mathrm{UFC} / \mathrm{ml})$. Las causas comunes de este recuento se pueden asociar a las inadecuadas prácticas de ordeño de los productores, el uso compartido de toallas no desechables, el uso del ternero en la estimulación de la glándula mamaria, no higienizar las ubres, utensilios con impurezas y tanques sucios (Bonifaz y Requelme, 2011; Álvarez et al., 2012). Además, factores físicos como la elevada temperatura y tiempo de permanencia de la leche en tanques de plástico durante el almacenamiento y transporte influyen en el contenido bacteriano.

\section{Conclusiones}

- Los criterios de calidad fisicoquímica de la leche producida en las ganaderías campesinas cumplen con los estándares mínimos de las normas nacionales, a excepción de la temperatura y calidad microbiológica, cuyos valores sobrepasan las normas nacionales e internacionales. 
- Parte de la leche acopiada no sería apta para el consumo humano, al contener un contaje microbiano superior al máximo permitido.

\section{Agradecimiento}

Los autores desean expresar su agradecimiento al $\mathrm{PhD}$ Carlos Vásquez por su valioso aporte en la redacción del documento y al PhD Marcos Barros por su colaboración en el análisis de los datos.

\section{Literatura Citada}

1. Alvarez-Fuentes G, Herrera-Haro J, Alonso-Bastida G, Barreras-Serrano A. 2012. Calidad de la leche cruda en unidades de producción familiar del sur de Ciudad de México. Arch Med Vet 44: 237-242. doi: 10.4067/S0301-732X2012000300005

2. Arango FO, Mazzeo MH, CaicedoErasob JC. 2011. Caracterización de la calidad y de la inocuidad de la leche cruda procesada por la industria láctea del departamento de Caldas. Vector 6: 79-84.

3. Bartl K, Gómez CA, Aufdermauer T, Garcia M, Kreuzer M, Hess H.D, Wettstein HR. 2008. Effect of diet type on performance and metabolic traits of Peruvian local and introduced cow types kept at 200 at $360 \mathrm{~m}$ of altitude. Livest Sci 122: 30-38. doi: 10.1016/ j.livsci.2008.07.022

4. Bobe G, Lindberg G, Freeman A, Beitz D. 2007. Composition of milk protein and milk fatty acids is stable for cows differing in genetic merit for milk production. J Dairy Sci 90: 3955-3960. doi: 10.3168/jds.2007-0099

5. Bonifaz N, Requelme N. 2011. Buenas prácticas de ordeño y la calidad higiénica de la leche en el Ecuador. Granja 14: 45-57.
6. Brassel F, Hidalgo F. 2007. Libre comercio y lácteos: la producción de leche en el Ecuador entre el mercado nacional y la globalización. Quito, Ecuador: SIPAE. 145 p.

7. Bernal LR, Rojas MA, Vázquez C, Espinoza A, Estrada J, Castelán O. 2007. Determinación de la calidad fisicoquímica de la leche cruda producida en sistemas campesinos en dos regiones del Estado de México. Vet México 38: 395-407.

8. Calderón A, García F, Martínez G. 2006. Indicadores de calidad de leches crudas en diferentes regiones de Colombia. Rev MVZCordoba 11: 725-737. doi: 10.21897/rmvz.457

9. Contero R. 2008. La calidad de la leche: un desafío en el Ecuador. Granja 7: 25-28. doi: 10.17163/lgr.n7.2008.05

10. CONVENIN 1315-79 N. V. 1979. Alimentos. Determinación del pH. (acidez iónica). Norma venezolana. [Internet]. Disponible en: http://www.sencamer.gob.ve/sencamer/normas/1315-79.pdf

11. Ferlay A, Martin B, Pradel P, Coulon $J B$, Chilliard Y. 2006. Influence of grass-based diets on milk fatty ccid composition and milk lipolytic system in Tarentaise and Montbeliarde cow breeds. J Dairy Sci 89: 4026-4041. doi: 10.3168/jds.S0022-0302(06)72446-8

12. Harvatine KJ, Boisclair YR, Bauman DE. 2009. Recent advances in the regulation of milk fat synthesis. Animal 3: 40-54. doi: 10.1017/S1751731108003133

13. Herrera L, Medina A, Naranjo G. 2004. Tutoría de la investigación científica. $4^{\circ}$ ed. Quito, Ecuador: Gráficas Corona Quito. $207 \mathrm{p}$.

14. INEN 0004, I. E. D. N. 1984. Leche y productos lácteos. Muestreo, 930. [Internet]. Disponible en: https:// archive.org/details/ec.nte.0004.1984/ page $/ \mathrm{n} 0$

15. INEN 0009, I. E. D. N. 2008. Leche cruda. Requisitos, 2411. [Internet]. Disponible en: https://archive.org/details/ ec.nte.0009.2008/page/n0 
16. INEN 0011, I. E. D. N. 1984. Leche. Determinación de la densidad relativa, 930. [Internet]. Disponible en: https:// archive.org/details/ec.nte.0011.1984/ page $/ \mathrm{n} 0$

17. INEN 0012, I. E. D. N. 1973. Leche, Determinación Del Contenido De Grasa, 38. [Internet]. Disponible en: https:// archive.org/details/ec.nte.0012.1973

18. INEN 0013, I. E. D. N. 1984. Leche. Determinación de la acidez titulable, 930. [Internet]. Disponible en: https:// archive.org/details/ec.nte.0013.1984

19. Linn JG. 1989. Altering the composition of milk through management practices. Feedstuffs 17: 16 .

20. Magariños H. 2000. Producción higiénica de la leche cruda. Guatemala: Producción y Servicios Incorporados. $95 \mathrm{p}$.

21. Mariscal P, Ibáñez, R, Gutiérrez M. 2013. Características microbiológicas de leche cruda de vaca en mercados de abasto de Trinidad, Bolivia. Agrociencias Amazonia 1: 18-24.

22. Ministerio de Agricultura, Ganadería, Acuacultura y Pesca. 2010. Acuerdo Ministerial N. ${ }^{\circ} 136$. [Internet]. Disponible en: http://www.agrocalidad.gob.ec/ documentos/dcz/acuerdo-136.pdf

23. Peláez P. 2003. Caracterización de los quesos con leche de cabra en la Isla de Tenerife. Influencia de factores am- bientales en el desarrollo de sus características organolépticas y físico-químicas. Tesis doctoral. Tenerife, España: Univ. de La Laguna. 394 p.

24. Petit HV. 2002. Digestion, milk production, milk composition, and blood composition of dairy cows fed whole flaxseed 1. J Dairy Sci 85: 1482-1490. doi: 10.3168/jds.S0022-0302(02)74217-3

25. Pico M. 2015. La producción de leche y su incidencia en los ingresos económicos de las familias productoras pertenecientes al consorcio de lácteos de Tungurahua Conlac-T, en el cantón Quero en el año 2015. Ambato: Ecuador: Univ. Tecnológica Indoamérica. $149 \mathrm{p}$.

26. Requelme N, Bonifaz N. 2012. Caracterización de sistemas de producción lechera de Ecuador. Granja 15: 55-68. doi: 10.17163/lgr.n15.2012.05

27. Rojas I, Méndez J, Portillo M, Rincón X, Martínez G, Contreras G. 2011. Efecto del polimorfismo genético de las proteínas lácteas sobre la producción y composición de la leche en ganado criollo limonero. Rev Cient 21: 517-523.

28. Vizcarra R. 2015. La leche del Ecuador. Historia de la lechería ecuatoriana. Quito, Ecuador: Centro de Industria Lactea CIL. 181 p. 